\title{
CUERPO Y DANZA: DEVENIR ACTIVO ENTRE ARTE Y POLÍTICA
}

\author{
Body and Dance: active Becoming between Art and Politics \\ Paz Carreño Hernández \\ Pontificia Universidad Católica de Chile, Santiago, Chile \\ pecarreno@uc.cl \\ Viviana Diaz Titelman \\ Pontificia Universidad Católica de Chile, Santiago, Chile \\ vdiaz3@uc.cl
}

\section{Resumen}

El presente artículo busca pensar el cuerpo y su movimiento en la danza. Respondiendo a la necesidad de pensar el cuerpo sin los límites que la forma le impone, la danza aparece como un fenómeno que obstaculiza la posibilidad de considerar la existencia determinada por su función y operatividad biológica. El cuerpo que danza, lejos de manifestar los límites del cuerpo, da cuenta de su posibilidad de devenir contra toda organización $u$ orden que lo fuerce a un estado de estabilidad. En este sentido, el argumento que recorre este escrito inicia definiendo la particularidad de la danza desde el punto de vista de Paul Valéry, para posteriormente desplegar el concepto de cuerpo que danza a partir de las consideraciones realizadas por Gilles Deleuze en su lectura de Friedrich Nietzsche. A partir de lo anterior, se sostiene que la danza en tanto cuerpo que danza es la posibilidad de un devenir activo de las fuerzas que en cada instante se transforma. Esto abre paso a una nueva consideración del cuerpo como creación, ya no anatómico, sino que múltiple, devorado por las fuerzas que le dan existencia. Esto, a su vez, entrega nuevas perspectivas para considerar distintas formas de existencia y de concebir un sujeto.

Palabras clave: danza, cuerpo, devenir, creación, sujeto, Deleuze.

\begin{abstract}
This article tries to rethink the body and its movement through the art of dance. Responding to the need of thinking of a body without the limits imposed by form, dance appears as a phenomenon that stands in the way of considering existence to be determined by function and biological operativity. The body that dances does not display its limits. It exposes its possibility of becoming against every organization and order that forces it towards a stable state. The argument of the article begins defining dance's peculiarity as it is described by Paul Valéry. It then elaborates on the concept of dancing body using Gilles Deleuze's lecture on Friedrich Nietzsche. In this analysis we sustain that the dancing body is a possibility for an active becoming of forces, a body that changes in every instant. This leads to a new consideration of the body. It unveils itself as creation and multiplicity, no longer pure anatomy, devoured by the forces that give it existence. This finally provides new perspectives from which to consider different forms of existence and to reconstruct the concept of subject.
\end{abstract}

Keywords: dance, body, becoming, creation, subject, Deleuze.

Fecha de Recepción: 01/07/2019 - Fecha de Aceptación: 26/11/2019 


\section{Introducción}

Estudiar filosóficamente al cuerpo se vuelve especialmente relevante desde la obra de Friedrich Nietzsche. En palabras de Roberto Espósito: "Su deconstrucción radical de las categorías del pensamiento moderno coincidió con un pensamiento sobre y desde el cuerpo [...] destinado a inaugurar un nuevo lenguaje" (92). El desafío de la filosofía, desde Nietzsche, ha sido reconciliar el cuerpo con su vitalidad para abrirle los espacios que le corresponden dentro de las discusiones sobre la existencia, la política, la razón y tantas otras más. La tarea es pensarlo liberado, lejos ya de la unidad corpórea organizada y estática que lo ha sofocado y que resulta ser la historia de la filosofía.

Estudiar al cuerpo es estudiarlo en movimiento. En esta última línea, la danza aparece como un espacio de presentación del cuerpo sumamente especial, pues ahí éste transgrede todos sus límites. En Filosofía de la danza Paul Valéry se dedica a pensar este fenómeno, pensar este cuerpo, cuerpo que presenta como cuerpo diferente al cotidiano y que así mismo siente y percibe. Dirá que la bailarina habita otro mundo, que la bailarina crea mundo, que la bailarina ha dejado el estado común de las cosas, y que esto lo interpela y lo transporta (2010). Pensaremos esta diferencia como una diferencia en la corporalidad: y es que la bailarina ha mutado cuerpo - es puro exceso. La bailarina cuando danza pone de manifiesto ese cuerpo que puede responder a las necesidades de la filosofía: cuerpo dinámico, cuerpo transgresor, cuerpo caótico, cuerpo indeterminado. La danza es una puerta para pensar una nueva perspectiva del cuerpo.

El presente artículo busca recuperar a través de la visión de cuerpo de Gilles Deleuze una perspectiva acerca del fenómeno de la danza tal como es expresado por Valéry. En esta dirección, la danza se presenta como un fenómeno del cuerpo con un potencial particular de creación. Los esfuerzos se dirigen hacia pensar el movimiento de la danza como una instancia especial de existencia; instancia activa y, por ello, siempre creadora. Para esto, a partir del concepto de fuerzas y devenir deleuziano se desarrolla un análisis de la danza como movimiento del cuerpo. Finalmente, vemos que la danza como manifestación activa del cuerpo y de sus fuerzas se enmarca indudablemente en una discusión política y ontológica, pues en el ideario deleuziano esto es constituyente del acto creativo.

\section{1.}

En Filosofía de la danza, Valéry reflexiona sobre el movimiento de la danza a partir de la observación de una bailarina. En el escrito se reflexiona acerca de la manera particular que tiene la danza para pensar y dar uso al cuerpo. Así, desde la perspectiva del espectador se abren las siguientes preguntas: ¿qué es lo excepcional en la danza? ¿Qué hace que una caminata danzada no sea lo mismo que esa misma caminata no danzada? ¿Por qué la mera presencia y quietud del cuerpo de la bailarina que está de pie no se 
percibe, no se siente como la quietud del cuerpo en la vida cotidiana? Valéry, asombrado por lo que llama "el estallido de vigor" del cuerpo de la bailarina (2000 110), señala que ese cuerpo que baila quiere alcanzar "un punto de gloria sobrenatural" (Ibid.). Es como si el cuerpo en la danza explorara una forma desconocida de habitarse, fuera de lo común y lo cotidiano, con una energía particular que transforma un simple movimiento en danza.

Ahora bien, ¿cómo explicamos esa transformación del movimiento? ¿Qué es lo que está detrás de este habitar el cuerpo de otro modo? Valéry reflexiona sobre esta pregunta aludiendo a que la diferencia radica particularmente en la energía de la acción de la bailarina; así, afirma que la danza es "la (auténtica) acción del cuerpo transferida a un mundo no práctico" (2010 47). El gesto de la mano que abre una puerta girando una perilla es distinto del gesto de la bailarina que tuerce la muñeca porque está bailando; la fuerza del cuerpo es diferente y por eso se percibe de otra manera. Son acciones iguales, pero simultáneamente distintas, que a su vez evocan sensaciones diferentes que, si bien no son fáciles de distinguir o referir de manera formal, son percibidas y afectan al espectador. Valéry atribuye lo anterior a que el movimiento de la bailarina excede la economía, no parece haber utilidad ni objetivo detrás de sus acciones: es moverse por moverse, bailar por bailar - exceso. ¿Cómo entender el cuerpo que no persigue un objetivo material, calculado o económico? ¿Qué es ser un cuerpo que se excede en cada movimiento?

Entenderemos que un cuerpo es un campo de tensión de las fuerzas. En palabras de Gilles Deleuze, "el cuerpo es un campo nutritivo disputado por una pluralidad de fuerzas [...], en relación de tensión unas con otras" (1998 60). El análisis que Deleuze desarrolla a partir de Nietzsche tematiza la cualidad de las fuerzas y su relación. Se distinguen dos tipos de interacción entre fuerzas: existen fuerzas activas y fuerzas reactivas. Así, la danza en cuanto fenómeno del cuerpo entiende a este último conforme a la disposición particular en que se relacionan las fuerzas que lo constituyen: "La relación de la fuerza con la fuerza es también la esencia de la fuerza; no nos preguntaremos, pues, cómo nace un cuerpo vivo, ya que todo cuerpo es viviente como producto «arbitrario» de las fuerzas que lo componen" (Deleuze 1998 61).

Particularmente en el caso de la danza, Valéry explica que la bailarina parece explorar un habitar el cuerpo diferente, no sujeto a la productividad, sino que siempre en transformación. El movimiento de la bailarina se siente distinto al movimiento cotidiano, pues es una tensión de fuerzas particular y especial que logra interpelar incluso a un espectador. Acorde a su visión respecto al caso de la danza, el cuerpo de la bailarina moviliza las fuerzas de manera tal que no se puede reducir su movimiento a ninguna finalidad. Esto convierte a la danza en un fenómeno en que el cuerpo transforma sus posibilidades más allá de la conservación y la economía, contrariamente a otras formas de cuerpo que se movilizan con objetivos materiales en particular: 
La bailarina está, pues, en otro mundo, que no es aquel que se pinta con nuestras miradas, sino el que ella teje con sus pasos y construye con sus gestos. Pero en ese mundo, los actos no tienen un fin externo; no hay objeto que asir, que alcanzar, que rechazar o del cual huir, ningún objeto que termine exactamente una acción y proporcione a los movimientos, primero, una dirección y una coordinación externas y, después, una conclusión nítida y certera" (Valéry 2010 48).

La fuerza del cuerpo en la danza debe ser diferente.

Una nueva visión de la corporalidad requiere, sin duda, constituir al cuerpo de una manera diferente. En vistas de esto Deleuze dirá que la cualidad de las fuerzas es comprensible y tiene un lugar en la medida en que las pensamos en relación. Tanto Nietzsche como Deleuze señalan que no hay fuerzas mejores o peores, debido a que constituyen un devenir como tal exclusivamente cuando se encuentran en relación unas con otras, nunca antes. En este sentido, Deleuze explica que el 'momento' de formación de un cuerpo - en otras palabras, el momento en que fuerzas se interceptan- es el instante en que las fuerzas entran en disputa, o bien dominando o bien siendo dominadas (1998 61). Entonces, solamente desde que el cuerpo está constituido como cuerpo, las fuerzas dominadas se pueden llamar reactivas y las dominantes activas (Ibid.). Así se entiende que en el instante del choque ninguna fuerza pierde o renuncia a su poder (Ibid.) ni se anulan entre sí. Por el contrario, lo que sucede en la relación de las fuerzas es lo que finalmente nos permite distinguir las cualidades en cuestión. Las fuerzas reactivas ejercen su potencia asegurando mecanismos y finalidades, ocupándose de las condiciones de vida y sus funciones: la conservación la adaptación, la utilidad; la estabilidad y equilibrio. Las fuerzas activas por su parte son de comportamiento, agresivo, conquistador y transformador, potencias que tienden al exceso y niegan el estado común de equilibrio, de estabilidad y de orden. Entonces se interceptan fuerzas formando puntos de tensión que devienen activos o reactivos dependiendo de la sensibilidad de las fuerzas que se relacionan (Deleuze 1998 91). En este sentido, el devenir es el movimiento que resulta de la interacción de las fuerzas. Nada asegura que serán las fuerzas activas las que dominen y las fuerzas reactivas las dominadas. De hecho, Deleuze aborda la obra de Nietzsche explicando que la historia de la humanidad ha sido la del devenir reactivo de las fuerzas: se han desarrollado las fuerzas reactivas de tal manera que separan a las fuerzas activas de su poder, invirtiendo la relación de dominación (Id.92).

Lo anterior se debe principalmente a que las fuerzas reactivas cuentan con la legitimidad de la conciencia, limitando, dividiendo e impidiendo cualquier exceso o desequilibrio propios de las fuerzas activas. En este contexto, Valéry argumenta que el cuerpo en la danza se opone al control ejercido por la conciencia, por lo que el choque de las fuerzas se convierte en un enfrentamiento entre lo inestable del cuerpo y la estabilidad de la conciencia (Valéry 2010 49). Entonces, devenir reactivo será el triunfo de la estabilidad y la conservación, mientras que el devenir activo implicará, en el caso 
de la danza, un bailar desinteresado, sin proyecto ni finalidad, que cautiva al espectador porque contagia el exceso de su vigor y energía. Así, Valéry explica que al espectador de la danza:

Le parece que esta persona que baila se encierra, de alguna manera, en una duración que ella misma engendra, una duración hecha toda de energía inmediata, de nada que pueda durar. Ella es lo inestable; derrocha inestabilidad, traspasa lo imposible, abusa de lo improbable y, a fuerza de negar, mediante su esfuerzo, el estado común de las cosas, crea en las mentes la idea de otro estado, un estado excepcional: un estado que es todo acción, una permanencia construida y consolidada por medio de una producción incesante de trabajo (Valéry 2010 48).

En la danza la bailarina crea un espacio tiempo fuera de lo común, que es un resultado involuntario de la relación de exceso que establece con su cuerpo en el momento de bailar. La bailarina, tomada completamente por la energía de la danza, se niega a permanecer en "el estado común de las cosas" (Valéry 2010 48). Este salir de un estado estable o común deja como resto un acto creativo: una creación artística distinta de la bailarina misma o del espectáculo mismo; es danza. Esta creación es la conquista de un espacio y tiempo sin soberanía. La danza no se contenta con el uso del cuerpo hacia una finalidad ni su conservación en un estado de equilibrio, sino que es un fluir persistente hacia otra forma de existencia; es el exceso de una transformación. Parece ser que la danza se encuentra entre la existencia formal y estable de la bailarina y aquel exceso insostenible pero incesante del cuerpo que se resiste a la limitación. Es el esfuerzo por habitar otras formas de vivir y de desplegar las fuerzas más allá de las posibilidades y la fatiga del cuerpo.

Así, la danza sería un devenir activo de las fuerzas: "Ahí está, por fin, en estado comparable al de la llama, en medio de los cambios más activos... Ya no cabe hablar de 'movimientos'... Ya no se distinguen sus actos de sus miembros... La mujer que había ahí ha sido devorada por figuras innumerables..." (Valéry 2000 110). Esto es justamente lo que hace sentir que la danza es danza y que no es cualquier otro tipo de movimiento: la danza es la simbiosis de acto y miembros, cambios activos de una multiplicidad de figuras. El cuerpo en la danza deviene activo en tanto empuja y transgrede sus propios límites y organizaciones, en tanto no limita sus posibilidades. Más aún, opera una transformación infinita, que de no ser por el cansancio, no recuperaría nunca una forma determinada.

El desarrollo que hemos caracterizado hasta aquí no pareciera ser aleatorio del todo. Que el devenir de la fuerza sea activo o reactivo tiene como correlato la sensibilidad de las fuerzas que se encuentran en relación. Deleuze explica: "Toda la sensibilidad no es más que un devenir de las fuerzas" (1998 92). De este modo, se sigue lógicamente que para cualquier devenir de fuerzas se requiere una sensibilidad en particular. Para que las fuerzas por fin devengan activas se necesita otra forma de sentir. La danza, entonces, sería una sensibilidad única que se derrama, requiere una 
disposición extraordinaria, transforma todo a su alrededor, contagia el vigor de la llama que la anima. La sensibilidad de la danza requiere impedir la calma: perpetuar la inestabilidad contra los límites del cuerpo. Entonces, esta sensibilidad es tal que las fuerzas no devienen reactivas. En este sentido la sensibilidad sería un concepto que explica el potencial devenir activo de las fuerzas.

\section{2.}

Cuando hablamos de sensibilidad, nos referimos al poder de afección. La relación que tengan las fuerzas estará determinada por su potencial de ser afectadas o de afectar su sensibilidad. En otras palabras, la sensibilidad es el pathos de las fuerzas (Deleuze 1998 91). Deleuze afirma que, contrariamente a lo que se piensa comúnmente, la sensibilidad no es una pasividad sino todo lo contrario: es esencialmente un poder. Este poder de ser afectado es lo que Nietzsche llama la voluntad de poder. Deleuze dirá: “La voluntad de poder se manifiesta como la sensibilidad de la fuerza" (Ibid.). El concepto de sensibilidad permite entender por qué la tensión de las fuerzas se resuelve de una $u$ otra manera. La sensibilidad de las fuerzas sirve para pensar un elemento otro que de manera no temporal (no le antecede cronológicamente, sino que como necesidad de su existencia) es anterior o inmanente a la relación de fuerzas o al cuerpo. Si no consideramos la sensibilidad de las fuerzas, estas serían contenidas y explicadas exclusivamente por la relación misma que las articula, como efecto absolutamente azaroso e imprevisible de sus choques. Pero es la sensibilidad la que le abre las puertas a la voluntad de poder a manifestarse. Cada tensión es única, y las distintas fuerzas -o ahora, diferentes sensibilidades - devienen nuevas tensiones.

Entonces, cuando nos preguntamos qué es el devenir activo de las fuerzas, lo primero que cabe señalar es que un devenir se acompaña de una sensibilidad. Pero la sensibilidad requiere un complemento, pues el devenir de las fuerzas no es un proceso completamente aleatorio. Es decir, que las fuerzas devengan activas o reactivas no es un hecho completamente azaroso. Deleuze dirá: "Este concepto victorioso de la fuerza requiere un complemento, y este complemento es algo interno, un querer interno" (1998 75). No hay fuerzas que se muevan sin una intensidad del querer: "La fuerza es quien puede, la voluntad de poder es quien quiere." (Deleuze 1998 75). Por consiguiente, existe un algo/un alguien que afirma un determinado devenir: un "yo quiero" (Deleuze 1998 75). Si hay voluntad hay quien quiere. Tras el poder de afectarse y de afectar hay una voluntad. En este sentido, la danza es una sensibilidad que moviliza un querer hacia la inestabilidad. Pero ¿es la bailarina quien quiere?, ¿es suya la voluntad de poder? Nos trasladamos entonces a la pregunta por el quién, o bien, a una pregunta por el sujeto. ¿Quién está ahí, donde el cuerpo se transforma en otro constantemente, donde se ha olvidado el cansancio, donde se quiere perpetuar la inestabilidad? 
En principio, es necesario constatar que no podemos afirmar la existencia de un sujeto formal, absoluto y trascendental, puesto que este es justamente el sujeto en el que Nietzsche identifica al hombre que ha devenido reactivo. La necesidad de constituirse como sujeto determinado es la necesidad del devenir reactivo. Según lo que señala Boyan Manchev (2010), el hecho de no poder afirmar un sujeto en términos tradicionales no impide la existencia de un sujeto, porque sujeto no es necesariamente una existencia absolutamente determinada. Con Nietzsche murió aquel sujeto de la historia de la filosofía antigua, medieval y moderna, a saber, el sujeto metafísico. Pero la bailarina en la medida en que danza no es este último sujeto. Es en realidad "un sujeto no sustancial, ocasional, oscilante, discontinuo: un sujeto en devenir" (Manchev 2010 1). Entendemos entonces que la bailarina deviene múltiple, deviene sujeto acontecimiental; deviene existencia en proceso. Pero, como sugiere Valéry, este devenir es insostenible.

Es insostenible porque cualquier devenir activo de las fuerzas está en un juego de transformación y cambio. Es tan inestable que se vuelve insostenible. Valéry señala en Filosofía de la Danza:

El hombre se dio cuenta de que poseía más vigor, más flexibilidad, más posibilidades articulares y musculares de los que requería para satisfacer las necesidades de su existencia y descubrió que algunos de esos movimientos le brindaban -por su frecuencia, sucesión y amplitud- un placer que llegaba a una especie de embriaguez, a veces tan intenso que solo el agotamiento total de sus fuerzas o cierto éxtasis del agotamiento podían interrumpir su delirio, su gasto motriz frenético" (2010 46).

Algo exterior al sujeto acontecimiental, exterior a la danza, lo fuerza al equilibrio. La embriaguez se agota, el delirio se vuelve conciencia, y el cuerpo vuelve a su cotidianidad. Un devenir activo es una fuerza intrínsecamente perpetua, pero que, por su infinitud, acaba. La bailarina no puede salir del sometimiento al sujeto metafísico permanentemente. Entonces, la danza no se reduce a la bailarina; la danza no es ella. El cuerpo de la danza no se cierra, no permanece: es acontecimiento. Ese cuerpo no es de nadie. La bailarina ya no es mero cuerpo biológico, cuerpo en operación, cuerpo para algo. Bailar es un acontecimiento del cuerpo de la bailarina, pero la danza es un acontecimiento que la excede. Simplemente, otro cuerpo: “Cualquier relación de fuerzas constituye un cuerpo: químico, biológico, social, político." (Deleuze 1998 60). Esto quizás es justamente lo que seduce a Valéry en la observación de la danza y lo que lo sumerge en una serie de sensaciones especiales: ha visto otra forma de ser cuerpo plasmada ahí donde la bailarina se mueve.

\section{3.}

La lectura de Valéry, en conjunto con las ideas de Deleuze respecto del cuerpo, permite pensar el cuerpo y el movimiento como un espacio y un lugar para el desarrollo de 
existencias que devienen activas. En particular, pareciera que en la danza el cuerpo desarrolla esa capacidad o ese potencial. En otras palabras, la danza podría ser la clave para pensar un devenir activo: sería la respuesta y la forma de existencia que se busca desde tiempos de Nietzsche. Sería la posibilidad de transformar la historia del devenir del hombre. Pero cuando pensamos al cuerpo no podemos aislarlo de la interferencia de un millón de fuerzas adicionales exteriores a lo que puede hacer la bailarina por sí sola. La danza no es un fenómeno puro, y así se dificulta la realización de este potencial activo. La danza no es la bailarina.

Valéry nos da una clave de pensamiento en este sentido. En Filosofía de la danza, Valéry, hace alusión a dos formas de expresión artística que se relacionan con el movimiento del cuerpo: la danza y la parada militar (2010 46). Si bien separamos estas puestas en escena intuitivamente y sin mucha dificultad, hay también muchas similitudes: en ambos casos hay una puesta en escena artística, y sobre todo, un movimiento no cotidiano del cuerpo. En otras palabras, hay bailarines. No obstante, parece imposible pensarlos como fenómenos iguales en tanto movimiento y performance. Parece existir una diferencia. Sin embargo, esta diferencia no radica en el cómo se mueven las articulaciones de la mano o las piernas, ni en la sensación psicológica que experimenta quien baile, quizás ni siquiera en la potencia de la fuerza que motiva su movimiento. Podemos pensar coreografías iguales, intenciones iguales, placeres iguales. Aun así y con toda semejanza, danza y parada militar son fenómenos diferentes. No cualquier movimiento del cuerpo puede ser danza, o incluso la danza puede danzar. En ese sentido, aquello que distingue a la parada militar de la danza - o aquello que hace de la danza el fenómeno que estamos pensando - no se encontraría en la obra artística misma como performance, sino que en el exceso que la danza significa y que traspasa los límites de la constitución de un cuerpo.

Que la danza sea danza responde a la expansión del cuerpo de la bailarina, un cuerpo que, fugándose, crea y llena otro espacio y tiempo, envuelto en una lógica y en una sensibilidad diferente. En la danza hay un cuerpo que ya no cabe dentro de su movimiento. Por lo tanto, la danza nos obliga a pensar la posibilidad de un cuerpo diferente, de un cuerpo otro, cuerpo danza; un cuerpo no sustancial ni formal. Ya no es cuerpo bailarín. Más bien, cuerpo en deformación. A fuerza de su deformación y en su suscitar movimiento, el cuerpo de la danza deviene activo. La bailarina se disuelve en cada movimiento y difumina sus límites. La danza ya no puede estar en la bailarina.

Ya no hablamos de la danza como un habitar el cuerpo biológico, sino de un cuerpo movilizado por sensibilidades que lo transforman y lo desorganizan, lo multiplican, lo vuelven otro en cada instante. Si retomamos a Manchev, ya no hablamos de un sujeto metafísico, sino de un sujeto como acontecimiento, un "cuerpo en vías de diferenciación" (Sauvagnargues 101). Cuerpo que se percibe pero no se ve, porque permanece en un movimiento que lo vuelve indeterminable, incodificable. En 
definitiva, es un cuerpo que se resiste a la formación: pura inestabilidad. Un cuerpo que se arroja contra y excede todos sus límites, y así, es creación.

Entonces, un movimiento puede dejar de ser danza en tanto no traspase la forma del cuerpo bailarina. Así, la diferencia entre parada militar y danza no está en cómo se mueven y exigen los cuerpos, tampoco en la puesta en escena misma ni en la intención comunicativa de la performance. La diferencia aparece allí donde el cuerpo, o bien es absolutamente tomado y determinado por la relación de fuerzas que lo movilizan, o bien escapa a dicha determinación. En otras palabras, la cuestión se encuentra en el concepto de cuerpo-danza como intensidad de una fuerza, como sensibilidad que difumina límites. La danza es danza en cuanto acontecimiento que va más allá de la acción corporal que nos es visible, más allá del espectáculo, más allá de la técnica y de la intención comunicativa: la danza como devenir activo de las fuerzas alcanza una dimensión política. La danza es propiamente danza como cuerpo político. El cuerpodanza se opone a la organización de lo estable y lo determinado como el concepto de cuerpo sin órganos de Deleuze y Guattari:

[...] pone de manifiesto el papel rector que cumple la filosofía del arte y la intrincación de las artes y la vida. La noción de cuerpo sin órganos se enriquece, entonces, con la crítica política de las organizaciones y de las líneas de estratificación que Deleuze elabora en conjunto con Guattari. El paso por la crítica de las organizaciones confirma la amplitud social y política que proporciona a Deleuze su encuentro con este último (Sauvagnargues 101-102).

Por el contrario, en el caso de la parada militar existe una exigencia radical y violenta de organización. En otras palabras, la parada militar es una performance de organización. La puesta en escena de la parada militar está completamente tomada por el orden y la ideología que le da sentido, y así anula cualquier posibilidad de caos y deformación. Todo esto implica que en la parada militar las fuerzas no escapan a la organización y a las instituciones políticas que reducen violentamente su forma y su significado. Es decir, no escapan a la "exposición de las relaciones de fuerzas" (Deleuze 2014 99). Más aún, la parada militar está constituida a partir de una estructura política rígida y totalizante como manifestación performática de la misma. Independientemente de cuál sea la sensibilidad o intensidad del cuerpo del militar que baila, la "institución" de la parada militar está dada por el establecimiento de una organización rígida sobre el cuerpo. Es el rostro (la visibilidad) del orden como totalización. En este sentido, se entiende que la parada militar no es un cuerpo otro como el cuerpo danza, sino que es un cuerpo ya codificado -siempre codificado, por definición codificado. Esta codificación total de la organización en la parada militar no deja espacio para el cuerpo como creación. Esto se debe a que no permite justamente aquello incodificable de la danza: organiza la desorganización, la reduce. La parada militar ha frustrado cualquier exceso del cuerpo. 
El caso de la danza es el del movimiento de un cuerpo que lucha contra la organización. Es pura creación y, por ello, escapa a la forma con energía puramente activa. En oposición a la parada militar, la danza como devenir activo es un proceso en que el sujeto constantemente deviene otro, se transforma y deforma en cada movimiento. En este sentido, lo entendemos como un proceso de subjetivación. El cuerpo-danza es incodificable, y ante cualquier intento de significación o formación el cuerpo danza transforma su existencia en otra, en movimiento continuo, en acontecimiento que es fruto de uno o múltiples devenires. Este devenir otro del cuerpodanza está dado por singularidades que interceptan lo estable y lo codificado desorganizándolo. Son la vía de escape a la determinación formal que la organización impone al cuerpo. En la medida en que interrumpen la organización, impiden su formación y movilizan las relaciones de fuerzas hacia nuevos espacios.

Muchas veces las singularidades son evanescentes e invisibles, pero generan afectos y percepciones. Así es como sentimos danza a la danza: es porque ha creado cuerpo, porque es proceso de subjetivación. El sujeto acontecimiento se transforma constantemente y deforma los límites impuestos una y otra vez en su devenir cuerpo danza, subjetivándose. Esto es lo que interpela a Valéry, que solo observa. Es que está viendo una manifestación de un devenir activo. El cuerpo de la bailarina que ve el autor no es cuerpo dominado, sino que es acción de la fuerza sobre sí misma: "La subjetivación es afecto de sí por sí. O si prefieren, el proceso, el movimiento, la operación por la cual la fuerza se pliega sobre sí misma para devenir principio regulador de la relación de fuerzas" (Deleuze 2015 128).

La subjetivación es entonces el proceso diferencial entre un devenir activo y un devenir reactivo y puede o no ser coartado en el proceso de creación artística:

[...]para que el arte se convierta en la operación de subjetivación, es preciso que ya no se conforme con constituir objetos particulares a los que se llamará obras de arte, es preciso que se convierta en el movimiento de la subjetivación en general. [...] Lo que está diciéndonos es que por más que la operación de la subjetivación derive de las relaciones de poder, se vuelve independiente, se autonomiza con el problema siguiente: quizás solo pueda autonomizarse si el arte toma un nuevo sentido, que ya no se reduzca a la producción de obras de arte y que se convierta en una verdadera producción de existencia (Deleuze 2015 130).

Así, la parada militar se constituye en tanto cuerpo político como violencia contra el proceso de subjetivación que constituye una danza. Esto es lo que nunca le permitirá devenir activa. Por el contrario, el cuerpo danza es un proceso de constante subjetivación contra la estabilidad y la organización, porque crea más allá de la obra de arte que lleva a cabo. Es insostenible y por tanto incodificable, es devenir siempre otro, movimiento perpetuo que intenta no sucumbir a la clausura ni a la economía biológica del cuerpo. 


\section{Conclusión}

Desde la visión de Valéry, la danza se ha comprendido como el estallido de vigor de un cuerpo. El movimiento transforma la función del cuerpo biológico en un cuerpo que conjura su inestabilidad, su incapacidad de mantenerse quieto incluso cuando la bailarina se detiene en un instante. La danza aparece como exceso que desemboca en cuerpo danza -invisible, pero siempre sensibilizante. En este sentido, esta caracterización de la danza se conjuga con el concepto de devenir activo de las fuerzas en tanto el cuerpo que danza abre espacios de deformación, de cambio e inestabilidad que impiden la consolidación de un cuerpo como límite. El cuerpo-danza se extiende en un territorio sin fronteras ni códigos, se transforma perpetuamente antes de ser definido y así, pese al rigor de su técnica, a la coreografía o a la puesta en escena misma, el cuerpo-danza abarca relaciones de fuerzas que no se limitan por el espectáculo, fuerzas sensibles, pero siempre activas.

En el fondo, dada la cualidad del devenir de sus fuerzas, que el cuerpo-danza devenga activo requiere una nueva interpretación de la danza. "Deleuze recoge así el proyecto de Nietzsche: «definir el cuerpo en devenir, en intensidad, como poder de afectar y de ser afectado, como Voluntad de potencia»" (Sauvagnargues 51). La danza como devenir activo nos obliga a reconsiderarla en tanto obra artística. La obra de arte 'dancística' es excedida por el devenir: manifiesta la exigencia de una nueva consideración de la existencia, y así, es inabarcable como mero espectáculo.

El cuerpo-danza como devenir activo pone en cuestión a su vez la necesidad de superar la concepción metafísica de sujeto para pensar el sujeto de la danza como acontecimiento. Esto significa pensar cualquier cuerpo creación como acontecimiento. Se requiere una desubjetivación y una resubjetivación que considere la existencia como un desarrollo, como una transformación siempre inconclusa y inacabable; como creación, como danza.

\section{Bibliografía}

Deleuze, Gilles. Nietzsche y la filosofía. Barcelona: Anagrama, 1998.

Deleuze, Gilles. Deseo y placer. Córdoba: Alción, 2004.

Deleuze, Gilles. El poder. Curso sobre Foucault. Tomo II. Buenos Aires: Cactus, 2014.

Deleuze, Gilles. La subjetivación. Curso sobre Foucault. Tomo III. Bs. Aires: Cactus, 2015.

Esposito, Roberto. Personas, cosas, cuerpos. Madrid: Trotta, 2017.

Manchev, Boyan. "Sujeto acontecimiental y acontecimiento-sujeto" Revista Latinoamericana del Colegio Internacional de Filosofía (2010): 32-42.

Sauvagnargues, Anne. Deleuze: del animal al arte. Buenos Aires: Amorrortu, 2006.

Valéry, Paul. Eupalinos o el arquitecto; el alma y la danza. Madrid: Machado Libros, 2000.

Valéry, Paul. "Filosofía de la danza". Revista de la Universidad de México (2010): 45-50. 